\title{
Current Trends in English-Kurdish Movie Subtitling
}

\author{
Harem Abdulla Majeed ${ }^{1}$, Kazi Hassan Saleh ${ }^{2}$ \\ ${ }^{1}$ College of Languages, University of Sulaimani, Sulaimani, Kurdistan Region, Iraq \\ ${ }^{2}$ College of Education and Language, Charmo University, Sulaimani, Kurdistan Region, Iraq
}

\begin{abstract}
This paper explores the current trends in audio-visual translation, in particular, movie subtitling from English into Sorani Kurdish in the Kurdistan Region of Iraq. It is hypothesized that subtitling English movies into Sorani Kurdish is performed using various methods, i.e. there is no one standard method that is adopted. This is based on the second hypothesis that the majority of subtitled movies into Sorani Kurdish are carried out by unprofessional subtitlers. The results of the study show that the majority of the subtitlers replace the English captions of previously subtitled movies by Kurdish translations, using different devices and word processors. Thus, the study exhibits that there is no one standard established method for subtitling English movies into Sorani Kurdish. It further shows that Kurdish subtitlers lack professionalism in terms of English-Kurdish subtitling.
\end{abstract}

Index Terms-Subtitling, Audio-visual Translation, EnglishKurdish Translation, Movie Translation.

\section{INTRODUCTION}

Audiovisual translation, undoubtedly, enjoys a large body of research within the field of Translation Studies. Yet its existence, practice as well as the current trend from English into Sorani Kurdish is understudied. Audio-visual translation and more specifically subtitling, in the Kurdistan region of Iraq, has recently become a widely practiced activity. This ranges from subtitling all types of movies, documentaries, plays, children's cartoons, and various TV programs (see Muhammad, 2016). Based on anecdotal evidence, English movies are subtitled into Sorani Kurdish unprofessionally, and they do not undergo any editing or quality assessment processes. This paper is not an endeavor to qualitatively investigate such subtitled movies, it rather aims to investigate the current practices as well as trends in movie subtitling among Kurdish subtitlers. To do so, it aims to see what methods subtitlers use in their subtitling activities and whether there is an established trend or established norms that are followed in Sorani Kurdish.

\section{II.METHODOLOGY}

To attest the previously mentioned hypotheses, fifteen subtitlers in the Kurdistan region of Iraq were asked to fill in a questionnaire form (Appendix 1). Subtitling and publishing movies were the criteria for selecting the participants. After selecting the subtitlers, they were either e-mailed the questionnaire forms or met in person. The questions in the form were exclusively devised to answer the questions raised in this study. Before discussing the methods of subtitling, questions were asked about the educational and professional background of the subtitlers to find out who are the performers of the subtitling process. The participants were asked about their motives for subtitling; and finally, the steps followed to subtitle a movie were discussed with the participants.

\section{Audiovisual Translation IN THE FRAMEWORK OF TRANSLATION STUDIES}

Upon exploring the literature of Translation Studies, it is apparent that research into audio-visual translation did not exist until Katharina Reiss felt the need for the fourth text-type to be included and as such she termed it 'audio-medial' (Reiss, 1971). However, she scarcely developed it, and indeed her definition seemed to refer more to fields such as advertising rather than movie and documentary translation. Holmes's map (1968) provides a category of 'medium-restricted' theories but does not mention audio-visual at all. Snell-Hornby (1988) links 'film' to 'literary translation in her integrated theory. 'The term 'constrained translation', specifically focusing on the nonverbal elements that marked out the audio-visual translation. Dirk Delabastita (1989), described AVT as a field that was 'still a virgin area of research' (quoted in Munday, 2012, p. 268-9). The field further developed in the 1990s and the 2000s. However, this is a very new topic in Kurdish, therefore this paper makes the initiative to explore it.

Journal of University of Human Development

Volume 5 No. 4(2019); DOI: 10.21928/juhd.v5n4y2019.pp1-6

Regular research paper: Received 4 July 2019; Accepted 7 August 2019; Published 15 September 2019

Corresponding author's e-mail: harem.majeed@univsul.edu.iq, kazi.saleh@univsul.edu.iq

Copyright (C) 2019 Harem Abdulla Majeed, Kazi Hassan Saleh. This is an open access article distributed under the Creative Commons

Attribution License (CC BY-NC-ND 4.0) 


\section{1) DEFINITION OF SUBTITLING}

Dictionary of Translation Studies defines subtitling "as the process of providing synchronized captions for movie and television dialogue" (Shuttleworth \& Cowie, 2014, p. 161). The captions consist of what the characters utter, either in the original language which the characters speak (intralingual subtitling) or in a language different from the one of the characters (interlingual subtitling) or in both (bilingual subtitling). The captions are normally shown on the lower part of the screen. As González explains, subtitling is a 'production of snippets of written text ... to be superimposed on visual footage" and is usually placed "near the bottom of the frame" (1998, p.14).

\section{2) TYPES OF SUBTITLING}

There are three main categories of subtitling from a linguistic point of view, which are: intralingual, interlingual, and bilingual subtitling. This mainstream categorization is supported by Baker (1998), Gottlieb (1997), and Dries (1995).

Intralingual or closed caption subtitling can be done for several purposes. It can be done for the benefit of the deaf and hard of hearing. It can also be beneficial for language learning purposes, especially when the audience wants to know how a spoken word or phrase is spelled, how some syllables are dropped out in speaking and how pronunciation can be improved. When there is a dialect diversity in a language, intralingual subtitling can step in to make sure that the speakers of different dialects fully understand what is being said. Finally, intralingual subtitling can be used in notices and announcements when the announcer wants to avoid the risk of missing details from the part of the audience such as numbers, dates, times, etc.

Interlingual (open caption) subtitling involves moving from the oral dialogue to one or two written lines and from one language to another. This kind of subtitling can be used for most of the purposes for which intralingual subtitling is used. Intralingual subtitling is generally used when the audience may not understand the source language (the original language of the audio-visual material).

Bilingual subtitling is used when captions in two languages are shown on the screen one of which can be the language which the characters utter.

\section{3) SUBTITLING IN SORANI KURDISH}

The scope of this study covers Sorani Kurdish which is understood by the majority of Kurds in Iraqi Kurdistan. This dialect has is an official language in Iraq. The political situation has provided the right of freedom of publication in Kurdish both in paper-based publications and televised programs.

Movie subtitling is an increasingly growing professional and social demand. According to SatExpat (2019), there are 118 TV channels in the Kurdistan region of Iraq six of which broadcast movies alone, whereas some others broadcast movies along with other programs. There are also several websites for movies, three of which exclusively feature Kurdish subtitled movies. This leads us to the next section which investigates who the subtitlers are.

\section{4) EDUCATIONAL BACKGROUND OF SUBTITLERS}

One of the essential constituents of the translation process is the translator. The translator's educational and professional background shapes the way the translation process is carried out. In the Kurdistan region, it is difficult to come across many translators who have studied Translation Studies because the majority of translation departments have been recently opened. Out of 15 public universities and 12 private universities, six universities offer undergraduate courses in translation, and three institutes offer a two-year diploma in translation. However, there are not many subtitlers who have studied Translation Studies. Only one participant of the questionnaire happened to have studied translation in an academic setting. Other translators range from secondary school students, high school students to university and institute students with no students at the graduate or postgraduate level.

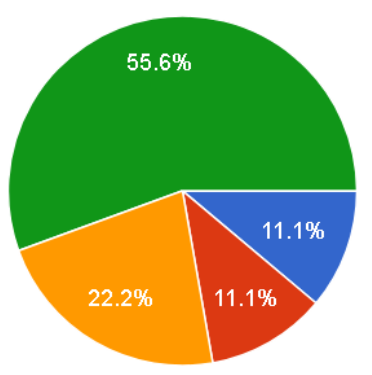

$$
\begin{aligned}
& \text { Secondary School } \\
& \text { High School } \\
& \text { Institute } \\
& \text { University } \\
& \text { MA or PhD }
\end{aligned}
$$

Figure 1: Education level of the subtitlers

\section{5) PROFESSIONAL BACKGROUND}

The terms "professional translator" is used in this section to refer to translators who pursue translation as a career. There is little chance for translators to work professionally in Iraqi Kurdistan because it is not a well-paid profession. Upon personal communication with many students, it becomes evident that the majority of translators and more specifically movie subtitlers are students. While the majority of the participants of the questionnaire have been translating and subtitling for more than two years, few of them could get a paid job as a translator, despite the fact that most of them have subtitled more than 50 movies so far.

There are only a few translation service providers in Kurdistan, the majority of which do legal translation. Those agencies do not offer audiovisual translation services, including subtitling, and as such, they do not hire subtitlers. Therefore, subtitlers have to look for other venues to work. One of the main opportunities for them is to work for a TV channel. As stated above, there are six TV channels which broadcast movies in addition to some other channels that broadcast movies along with other programs. According to interviews carried out with editors from TV channels, "thirty to fifty translators would be enough for those channels". The other opportunity is to work 
for movie websites as volunteers and very rarely for movie festivals. Thus, there are very few professional subtitlers in Kurdistan who do translation as a paid occupation. One can argue that if they are not paid for the subtitling they perform, why do they do it? This is a significant question which will be discussed and answered in the next section.

\section{6) MOTIVES FOR SUBTITLING}

The previous section referred to the market need in Kurdistan in relation to subtitling, as well as the conditions for which subtitlers work. However, it pointed to the fact that the majority of subtitlers work for free and thus are not paid for the services they provide. It is worthwhile here to find out why subtitlers choose to do an unpaid job. The majority (75\%) of the participants admitted that they do not earn any money for subtitling movies, the remaining $(25 \%)$ claimed that sometimes they get paid and other times do it for free. They also claim that the amount they get is not worth the effort they exert to subtitle a movie. The following is the list of the main motives for subtitling.

\section{A. SUBTITLING AS A HOBBY}

While millions of people enjoy watching movies, there seems to be others who enjoy subtitling movies. The majority of volunteer translators choose the movies that they like. Subtitling those movies provides a chance to watch the movie more than once and get a more in-depth understanding. Today, it is not uncommon that people not only watch movies, but they also like to share them with others. This might be rewarding enough for some translators regardless of whether they get paid or not.

\section{B. LANGUAGE LEARNING}

It cannot be denied that translation was traditionally a branch of linguistics which was practiced for language learning purposes (Pym et al., 2005). The same is true of subtitling. Several participants of the questionnaire admitted that they subtitle movies to improve their English language proficiency. Translating, in general, requires a comprehensive understanding of the source text, which, in effect, implies that translators should check-up for any unfamiliar word or expression. While this paper is not intended to assess the quality of translators and their subtitled movies, this phenomenon can be one reason that many people complain about the quality of the subtitles. It is interesting to know that, although the movies are subtitled for language learning purposes, they are actually published on different platforms such as TV channels (both local and satellite) and websites. This phenomenon can be further investigated in future studies.

It can be argued that subtitling movies can be a better practice for language learning than translating texts and books (or parts of books) because movies and audio-visual materials help translators to have a better understanding and knowledge about the source language culture. If language courses are to use translation as a language learning technique, they might as well consider subtitling as an effective strategy. This method is an already common trend among language learners and it seems to be more enjoyable; otherwise, no one is willing to subtitle large numbers of movies without being paid a penny.

\section{C.INTERNSHIP}

Several translators do subtitling as a kind of internship. They try to subtitle and publish as many movies as they can so that they get known and recognized in the hope that they will get hired when there is a vacancy such as in TV stations, private media companies/agencies, or movie festivals.

\section{D.PAYING BACK TO THE COMMUNITY}

This motive can be included in point number one since the motive here is the same idea of sharing, but it is discussed in a separate point because the translators feel that it is more than sharing or recommending, they feel that they ought to help those who love watching movies but cannot understand the original language of the movie. The translators categorize this motive as serving the community or paying back to it.

\section{7) STEPS OF THE TRANSLATION PROCESS}

There are several ways to analyze the steps taken in the translation process, but Christiane Nord's (1988) intercultural text transfer is one of the most comprehensive approaches. Nord's definition for "translation" covers all kinds of translation/interpreting including, all genres and text types.

Before the birth of a translated text, there are several steps that have already taken place and several people might have been involved. First, there is the source text producer who might be the one who has initiated the process, or s/he has been asked by someone else to initiate the production of the source text.

There is an optional " $\mathrm{X}$ " constituent after the source text producer and the sender. This $X$ constituent is the one who adapts the source text to a certain format before it has been published. While it is optional in Nord's diagram, it is the main constituent in the process of movie script production. The $\mathrm{X}$ constituent is the agency who adapts the source text to a movie script.

When the movie is produced in the source language it comes with the source language subtitles (intralingual subtitling) in the majority of the cases. The production of the intralingual subtitles can be due to the legal obligation of the country in which the movie is produced, or any other purpose.

In the case when the movie production company does not provide the script or the intralingual subtitling, it is done by other companies and agencies for their own purposes

In essence, the production of intralingual subtitles is half the way to the production of the subtitles in the target language(s) since the translator needs not to bother to translate from the voice of the movie characters which requires a great amount of time and effort. Movie subtitles are generally available in public domains. Afterward, the following agents carry out different tasks for the production of the translated subtitles:

\section{A. INITIATOR}

The translation process usually starts with an initiator who is the one who chooses a text, a movie to be translated in a certain way according to some specific instructions which s/he sets up. In other words, there are two main elements: choosing the movie, and providing instructions according to which the movie is to be translated (i.e. translation brief). 
There are two main scenarios for initiating a translation process. In the first one, an initiator is a different person from the translator, in the case of subtitling, the initiator can be a TV channel, a movie festival organizer or a website. These parties choose a movie that suits their purposes and ideologies. For example, a religious channel chooses a movie that does not go against the religious standards of that channel. In the second scenario, however, the initiator and the translator are the same person. For example, a translator decides to subtitle a movie, a particular series, or any other audio-visual material after watching it simply because s/he likes it, and s/he thinks it might be a good idea to let others watch it in the target language.

In both scenarios, there are some instructions, either written or spoken, which shape the way the source text is translated and how the target text should be. TV channels have some specific instructions such as toning down swear words and culturally inappropriate expressions, while websites have little or no instructions for two reasons. First, some websites are not official (at least in the context of Kurdish society) and have fewer responsibilities than TV channels. Second, the websites do not pay translators so they give translators more freedom to translate the way they want. In this case, the instructions (the translation brief) are more subjective and thus are set according to the translator's own ideology.

\section{B. TRANSLATOR/SUBTITLER}

Although there is not only one way to carry out a subtitling task, the patterns or regularities which the majority of the translators follow are described in this section as according to the analysis of the questionnaires. The majority of the participants claim that they watch the movie before starting the translation process, in some cases, they watch the movie more than once. Then, they download the script (source language subtitles) in SRT format which is available online for free. The SRT document contains all the dialogues which are spoken by the actors accompanied by the time in which they are spoken and the period that captions stay on the screen.

SRT documents can be handled by any word processing applications such as Notepad, Microsoft Word, etc., and they contain the source language subtitles. The whole translation process can be carried out only by replacing the source language subtitles with the target language subtitles. Unlike what is commonly thought, many translators do not use computers for replacing the source text with the target text, they simply do so using mobile phone applications such as Subscene and Subeditor. After the translation and the replacement tasks, the process is finished from the side of the translator and they send the new copy of the SRT document to the editor of the website or the TV channel.

One of the most important aspects of the translation process is time. Spending too much time on a translation task, on the one hand, negatively affects the translator's productivity and the amount of money s/he can earn. On the other hand, not spending enough time on the task can also negatively affect the quality of the translation product. Therefore, a translator needs to make a balance between productivity and quality keeping in mind that translation is a mentally exhausting mission that requires the translator to think about the selection of every single word. As a result, translators in general cannot work for long periods of time without taking breaks. The working periods and the translator's performance change according to the extent they are interested in what they do. The participants of the questionnaire claim that it usually takes more than two days to translate a movie subtitle and can take up to a month in some cases (especially when the translation task is unpaid). With that being said, there are two exceptions due to which the movie is translated in one day. First, when the movie is a part of a series that is presented daily or weekly and there are other competitive websites or channels. The second case is that when the translator really likes the movie and enjoys translating it.

Translators tend to take breaks within the translation sessions (i.e. on the same working day) the duration and frequency of which are also determined by the abovementioned factors.

\section{C.EDITOR}

The editor's part starts when the translator finishes the translation process and replaces the source text with the target text and sends the SRT file to the editor.

Editors check to see whether the video file resolution that ranges from 480p, 720p, 1080p and recently 2000p matches the translated SRT file. If the movie resolution is $480 \mathrm{p}$, the translated SRT file should be one that is designed for the 480p format version of the video, otherwise, there will be delays (lags) or advance in the presentation of the captions in a way that the captions do not match the video timing. This is similarly true for all other video resolutions and formats such as BrRip, DVDrip, Blue-ray, etc. If the versions match, the editor can proceed to the next step. If not, s/he sends back the translation to the translator accompanied by the right version of the SRT document so that the translator can copy and paste the texts from the previous version he produced to the right version of the SRT file.

\section{D.REVISER}

What is a regularly repeated pattern for checking the quality of the translation is that the editor chooses a sample of 100 to 200 sentences from the translation, s/he compares them to the source text and checks the quality of the translation. The quality assessment is not done in a scientific way, i.e. there is not any fixed criteria, rubrics or model for assessment. It is enough for the target text to be understandable in the target culture and close to the source text. If the translator passes in the assessment of his/her first couple of movies, his/her movies are not proofread any more in future translations. On the other hand, if the translation is not understandable, it will be sent back to the translator for further improvements to be carried out.

An important question that is raised here is that "who is the proof-reader?" If the translation is done for a TV channel, the proof-reader is the chief translator from the TV channel who has passed in the assessment of his/her first couple of movies. If the translator is the editor of the website, they are usually experienced translators in the domain of subtitling with translation knowledge and expertise. If the proof-reader is not the editor him/herself, the assessment is assigned to another translator who has passed in the assessment of his/her first couple of movies.

One of the problems editors face is the Kurdish font. Older versions of Microsoft Windows and other operating systems did not support Kurdish font (alphabet). One had to use regular 
Arabic (101) or (102) keyboard with some amendments for the alphabetic letters that are in Kurdish but not in Arabic. Later, Kurdish Unicode fonts were introduced which are supported by Microsoft Windows and different applications and platforms. There are two variations of Kurdish Unicode Keyboards, one of them follows the Arabic alphabet on the keyboard of computers and the other one follows the English alphabet on computer keyboards. However, with Windows 8 versions, Microsoft windows started supporting Kurdish Unicode keyboard known as Sorani Kurdish.

All the Unicode Kurdish Keyboards including the one that follows the Arabic alphabet, the one that follows English Alphabet, and the Sorani Kurdish from Microsoft Windows are supported in the SRT file type and they do not cause any problem.

However, the use of standard Arabic (101) or (102) keyboard with the amendments is still common. The most common Kurdish fonts to write Kurdish using Arabic Keyboard are Ali-K fonts family. However, these fonts are not supported in SRT documents and cannot be decoded.

An editor has to make sure that the translator has used the right Unicode font, otherwise, s/he has to convert the fonts using online or offline applications designed for that purpose so that the text can be processed in SRT files.

The aforementioned steps are taken if the subtitling is done using a computer, but if the subtitling was done using a smartphone, will there be any inconvenience? The answer is surprisingly "No!" if the translators know how to use the smartphone application efficiently. Smartphones make use of Kurdish Unicode fonts for writing in Kurdish. A Unicode keyboard can write anywhere no matter for which language the spot is designed. As mentioned earlier, the source text SRT files are in English and the text direction is left to right, while the direction of Kurdish is right to left. Thus, translating using smartphones can cause difficulty for the editors when they want to decode the SRT file and merge it with the video especially with the punctuation marks. The applications get confused when they come across a punctuation mark written in a Kurdish sentence. Punctuation mark comes at the left end of the sentence, while the whole document was in English and the punctuation marks came at the right end of the sentence. To avoid this problem, the editor informs the smartphone users to put the punctuation marks at the beginning of the Kurdish sentence (instead of the end) so that they would appear at the end of the sentences when decoded.

After checking all the above-mentioned conditions and when everything is all right, the editor is ready to merge the SRT and the video files using applications designed for that purpose, such as MKVToolNix. Finally, the subtitled movie is ready to be published online or broadcast on TV. However, many international websites and companies do not merge the captions with the video. They make different target language SRT files available with the video file so that the audience can choose the language(s) they prefer. On the contrary, almost all Kurdish agencies, TV channels, and websites merge the captions from the SRT file with the video file so that they cannot be separated later.

\section{CONCLUSIONS}

This study has focused on investigating current trends in English-Kurdish subtitling in the Kurdistan region of Iraq, considering how movie subtitling is performed and what methods are used. For this purpose, fifteen translators (subtitlers) were asked to fill in a questionnaire form to discuss the way they carry out the subtitling process. The study revealed that there is not one fixed pattern for subtitling movies in Kurdistan region. The majority of translators are self-taught and unprofessional (not subtitling as a paid occupation). They obtain the ready English subtitles online, and they replace the English subtitles with their Kurdish translations, either using computers or smartphones. It also revealed that the majority of translations are published unrevised; instead, plenty of time is spent fixing punctuation marks and font problems. The former caused by using smartphones and the latter by not using Unicode fonts. The findings identified that subtitlers have four main motives for subtitling, which are: enjoying the subtitling activity, learning English, improving professional skills, and paying back to the community.

\section{REFERENCES}

Baker, M., \& Saldanha, G. (1988). Routledge Encyclopedia of Translation Studied. Oxford: Routledge.

Dries, J. (1995). European Institute for the Media. Manchester

Gonzalez, L. P. (1998). Audiovisual Translation. In M. Baker, \& G. Saldanha (Eds.), Routledge Encyclopedia of Translation Studies (pp. 1320). New York: Routledge.

Gottlieb, H. (1997). Subtitles, Translation, and Idioms. Copenhagen.: The University of Copenhagen.

Holmes, J. (1968/1988). Translated! Papers on literary translation and translation studies. Amsterdam: Rodopi.

Muhammad, H. (2016). Semantic Loss in Translating Movie Subtitles from English into Kurdish.

Munday, J. (2012). Introducing Translation Studies (3rd ed.). New York: Routledge.

Nord, C. (1988/2005). Text Analysis in Translation: Theory, Methodology, and Didactic Application of a Model for Translation-Oriented Text Analysis (2nd ed.). Netherlands: Printforce.

Pym, A. (2005). New Trends in Translation Studies. In Honour of Kinga. (K. K. Kinga Klaudy, Ed.) Budapest: Akadémiai Kiadó.

Reiss, K. (1971/2000). Translation Criticism-The Potentials and Limitations: Categories and Criteria for Translation Quality Assessment (3rd ed.). Manchester : St. Jerome Pub.

SatExpat. (2019). List of free-to-air satellite Kurdish-language television channels. Retrieved from Television Satellite Channels: http://en.satexpat.com/tv/kurdistan/

Shuttleworth, M., \& Cowie, M. (2014). Dictionary of Translation Studies. New York: Routledge.

Snell-Hornby, M. (1988). The Turns of Translation Studies. Amsterdam: J. Benjamins Pub. 


\section{APPENDIX 1 - QUESTIONNAIRE}

\section{Please note}

- The process takes 15 to 20 minutes depending on your answers.

- You can skip answering any question.

- You can withdraw at any time.

- Your personal information will remain confidential.

- Your answers will be used for the above-mentioned purpose alone.

- By signing below, you show your consent to participate in the questionnaire.

- Your name and personal information will remain confidential.

Full name: Signature:

Phone no: Date:

1. Where do you live?

Mark only one oval.
Sulaimani
Erbil
Halabja
Others

2. What is your educational level?

Mark only one oval.

\begin{tabular}{|l|l}
\hline & Secondary School \\
High School \\
Institute \\
& University \\
& MA or PhD
\end{tabular}

3. Have you studied Translation Studies?

Mark only one oval.

Yes

No

4. If "yes", how relevant your study in Translation Studies is to subtitling?

Mark only one oval.

Little

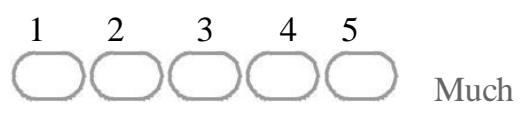

5. How long have you been translating?

6. How long have you been in audio-visual

translating/subtitling?

7. Can you give an approximate number of movies you have subtitled?

8. What is your aim behind subtitling?

Check all that apply.

Improving English language proficiency

\section{Amateur}

Business

Internship

Other:
7. Do you get paid for subtitling movies?

Mark only one oval.

$\square$ Yes

No

Sometimes

8. If yes, do you think the amount you get is suitable for the effort you exert?

Mark only one oval.

$\square$ Yes

No

9. If no, why do you do it?

10. Do you have any other job?

Check all that apply.

Yes, translation-related

Yes, non-translation-related

Student

No

11. How interested are you in subtitling?

Mark only one oval.

Little

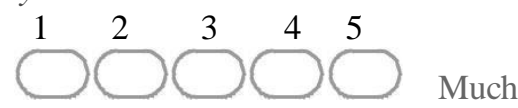

12. Where do the movies you subtitle get published?

Check all that apply.

$\square$ Nowhere

Websites

TV channels, local

TV channels, satellite

Film Festivals

13. What are the steps you take to subtitle a movie?

14. How do you choose the movies?

15. Is there any filter on certain movie types or contents? Mark only one oval.
$\square$ Yes
No
Sometimes

16. How do you get the script? in which format?

17. Do you only translate the text or you do the technical aspects as well?

Mark only one oval.

$\square$ Only translating

Translating and editing

18. How do you put the script on the video?

19. How long does it take to translate a movie subtitle? Days, hours, how do you split the time?

20. Does anyone revise your translation, for what purposes?

21. Do you use any software? Why do you use it?

22. Which font do you use? Does it cause any difficulty? 